\title{
Microalgae-based processes as an energy efficient platform for water reclamation and resource recovery
}

\author{
María del Rosario Rodero ${ }^{1,2}$, Roxana Ángeles ${ }^{1,2}$, Victor Pérez ${ }^{1,2}$, Juan Gancedo ${ }^{1}$, Silvia Bolado ${ }^{1,2}$, Raque \\ Lebrero $^{1,2}$, Raúl Muñoz ${ }^{1,2}$ \\ ${ }^{1}$ Department of Chemical Engineering and Environmental Technology. School of Industrial Engineering. Venue Dr. Mergelina. University of \\ Valladolid. C/Dr. Mergelina, s/n, 47011. mrrodero@iq.uva.es, roxana@iq.uva.es, victor.perez@iq.uva.es, raquel.lebrero@iq.uva.es, \\ jgancedoverdejo@hotmail.es, mutora@iq.uva.es \\ 2 Institute of Sustainable Processes, University of Valladolid, 47011, Valladolid, Spain
}

\begin{abstract}
Highlights:
Microalgae provide a low-cost and enviromnentally friendly oxygenation

Enhanced nutrient recovery as a result of the dual photoautotrophic and heterotrophic metabolism

Microalgae can turn the energy balance of conventional wastewater treatment into positive

Microalgae-based processes can be engineered into multiple configurations

Wastewater treatment and biogas upgrading can be combined in algal-bacterial photobioreactors
\end{abstract}

Keywords: nutrient recovery, microalgae, photobioreactors, wastewater treatment

\section{Introduction to microalgae-based wastewater treatment}

The treatment of urban wastewater is nowadays carried out using activated sludge processes due to their high robustness, efficient removal of carbon, nitrogen and phosphorus at low-moderate temperatures, and extensive experience in their design and operation. However, activated sludge processes still exhibit a negative energy balance, low nutrient recovery and a high carbon footprint. These processes are particularly inefficient from an energy point of view in wastewater treatment plants with population sizes of 1000-20000 inhabitants equivalent. On the other hand, the treatment of wastewater in algal-bacterial photobioreactors based on solar-driven photosynthetic oxygenation of the process results in a cost-efficient elimination of contaminants, a high recovery of nutrients and a positive energy balance. Figure 1 shows the energy balance for the treatment of $100 \mathrm{~g}$ of chemical oxygen demand (COD) using activated sludge processes and a microalgae-based wastewater treatment process (Alcantara et al. 2015).
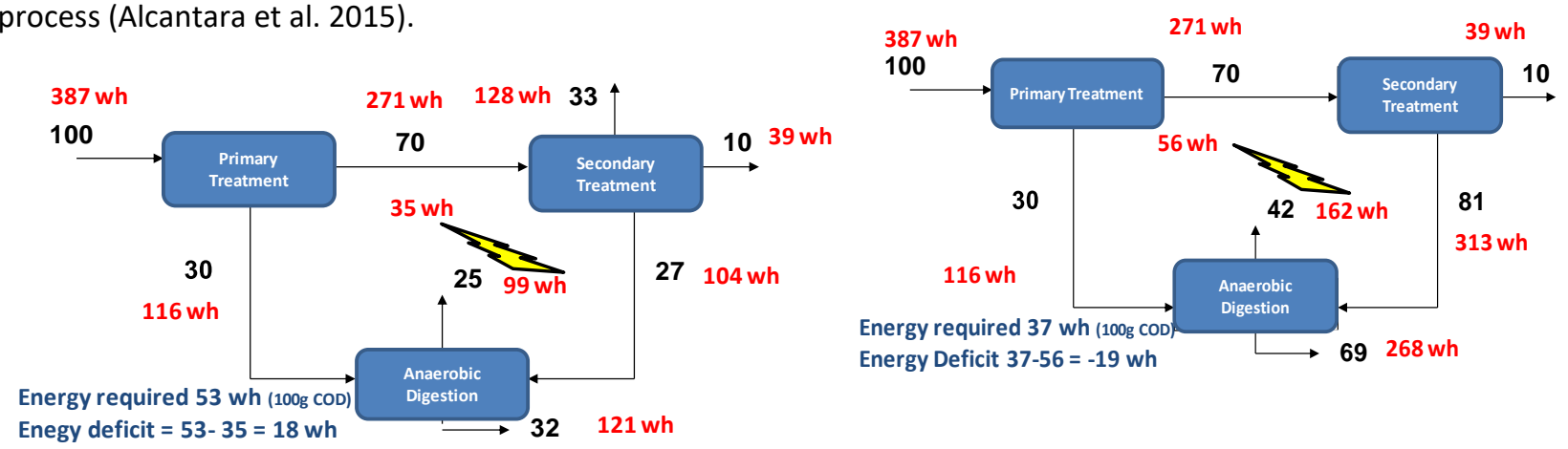

Figure 1. Energy balance for the treatment of $100 \mathrm{~g}$ of COD in an activated sludge process (left) and microalgae (right). 